\title{
Application of bacteriophage as food preservative to control enteropathogenic Escherichia coli (EPEC)
}

\author{
Diana Elizabeth Waturangi ${ }^{1 *}\left(\mathbb{0}\right.$, Cecillia Pingkan Kasriady², Geofany Guntama², Amelinda Minerva Sahulata ${ }^{2}$, \\ Diana Lestari ${ }^{2}$ and Stella Magdalena²
}

\begin{abstract}
Objectives: This study was conducted to characterize lytic bacteriophages infecting enteropathogenic Escherichia coli (EPEC) on several types of food and analyze their ability as phage biocontrol to be used as a food preservative. Characterization was done for bacteriophage morphology and stability, along with the determination of minimum multiplicity of infection (miMOI), and application of bacteriophage in the food matrix.

Results: Out of the five samples, BL EPEC bacteriophage exhibited the highest titer of $2.05 \times 10^{9} \mathrm{PFU} / \mathrm{mL}$, with a wide range of $\mathrm{pH}$ tolerance, and high thermal tolerance. BL EPEC also showed the least reduction after $168 \mathrm{~h}$ of incubation, with a rate of $0.90 \times 10^{-3} \log _{10}$ per hour. Bacteriophages from BL EPEC and CS EPEC showed an ideal value of miMOI of 0.01 . As a food preservative, BL EPEC bacteriophage was able to reduce bacteria in food samples with a reduction above $0.24 \log _{10}$ in lettuce and approximately $1.84 \log _{10}$ in milk. From this study we found that BLEPEC bacteriophage showed the greatest potential to be used as phage biocontrol to improve food safety
\end{abstract}

Keywords: Bacteriophages, Enteropathogenic Escherichia coli (EPEC), Foodborne disease, Food preservative

\section{Introduction}

Pathogenic bacteria such as Enteropathogenic Escherichia coli (EPEC) are one of the main cause of foodborne disease, and it also has been reported as the major source of many foodborne disease cases. In 2010, it was estimated that foodborne disease had caused the death of more than $4,20,000$ people globally $[1,2]$. EPEC can infect and transmit into the human body through contaminated food due to the poor sanitation, therefore it can bring a big impact on public health, especially outbreak diseases [3]. Many strategies have been used to reduce the contamination of pathogenic bacteria in food, such as the use of various chemical preservatives, but some of them

\footnotetext{
*Correspondence: diana.waturangi@atmajaya.ac.id

${ }^{1}$ Department of Biotechnology, Atma Jaya Catholic University

of Indonesia, Jalan Jenderal Sudirman 12930, Jakarta, Indonesia

Full list of author information is available at the end of the article
}

came with unwanted side effects. Therefore, an alternative solution offered is to use bacteriophage to control food borne pathogens for food preservatives to improve food safety [4].

Bacteriophages have the potency to be used as a natural food preservative mainly due to their high specificity, self-replicating, and rapid killing property towards the pathogenic bacteria [5]. In applying bacteriophages in various forms of food, it should have characteristics that are suitable to be used as a food preservative, such as lytic activity towards pathogenic bacteria, not altering the quality of the food $[6,7]$ and have a broad spectrum to cover all important target bacteria [8]. The objectives of this research were to characterize lytic bacteriophages infecting EPEC, morphology determination, stability and to analyze their effectiveness on several types of food. 


\section{Main text \\ Methods \\ Bacterial refreshment}

Enteropathogenic Escherichia coli Nmr-2 from Namru-2 was used in this research as the bacterial host. EPEC Nmr-2 was inoculated onto Luria Bertani (LB) agar and incubated at $37^{\circ} \mathrm{C}$ overnight.

\section{Bacteriophage enrichment and purification}

EPEC Nmr-2 was inoculated into LB broth and incubated for $6-8 \mathrm{~h}$ to obtain the mid-log growth phase [9]. We used 5 bacteriophage of EPEC which were isolated from previous studies including (K EPEC) from ketoprak, (BI EPEC) from beef intestine (BL EPEC) from beef lung, (CI EPEC) from chicken intestine and (CS EPEC) from chicken skin. Bacteriophage was enriched by adding previously grown bacteria and specific bacteriophage into LB broth and incubated overnight [10]. After enrichment, the mixture was centrifuged at $10,000 \times g$ for $10 \mathrm{~min}$. The supernatant was filtered using a $0.22 \mu \mathrm{m}$ pore-size membrane syringe filter [9].

\section{Bacteriophage titer determination}

Titer was determined using the double-agar overlay method. Bacteriophage lysate was diluted using SM buffer with a series of tenfold dilution. Visible plaque was calculated and converted into plaque forming unit per milliliter (PFU/mL) [9].

\section{pH and thermal stability assay}

For $\mathrm{pH}$ stability assay, bacteriophage lysate was added into a series of tubes containing SM buffers ( $\mathrm{pH} \mathrm{2,} \mathrm{4,} \mathrm{6,}$ $8,10,12$, and 14). As for thermal stability assay, bacteriophage lysate was incubated at different temperatures (4, $25,37,45,55,60,65$, and $\left.70{ }^{\circ} \mathrm{C}\right)$. Titer was determined using the double-layer agar method [11].

\section{Morphology analysis}

Bacteriophage morphology was determined using the Transmission Electron Microscope (TEM) at Eijkman Institute of Molecular Biology, Jakarta. Bacteriophage lysate was dropped onto a 400-mesh grid and was negatively stained using $2 \%(\mathrm{w} / \mathrm{v})$ uranyl acetate on carboncoated grids. Grids were observed using JEM-1010 TEM (JEOL, Tokyo, Japan) at magnification of $\times 30,000$ [10].

\section{Storage stability analysis}

Bacteriophage stability was determined by incubating bacteriophage lysates at $120 \mathrm{rpm}, 37{ }^{\circ} \mathrm{C}$ and were taken in $0,1,5$, and 7 days. Titer was determined using the double-layer agar method [11]. Bacteriophage reduction rate was calculated with the formula below:

Reduction rate $=\frac{T-T_{0}}{t}$
$\mathrm{T}=$ Bacteriophage titer after $168 \mathrm{~h}$ of incubation.

$\mathrm{T}_{0}=$ Bacteriophage initial titer.

$\mathrm{t}=$ Time of incubation.

Determination of minimum multiplicity of infection (miMOI) EPEC Nmr-2 was grown in LB broth overnight. Absorbance of bacteria was measured at $\mathrm{OD}_{600}=0.132$ $\left(\sim 10^{8} \mathrm{CFU} / \mathrm{mL}\right)$ and diluted to $10^{6} \mathrm{CFU} / \mathrm{mL}$. Bacteriophage sample was diluted to $10^{3} \mathrm{PFU} / \mathrm{mL}$. Bacteria and bacteriophage lysates were added into microplate wells with MOI ratio from 0.001 to 1000 and were done in duplicate. Absorbance was measured using a microplate reader for $12 \mathrm{~h}$ [12].

\section{Application of bacteriophage}

Shrimp, chicken meat, milk, and tofu were sterilized using an autoclave, whereas lettuce was sprayed with $70 \%$ alcohol. EPEC Nmr-2 was grown in LB broth and diluted to $10^{6} \mathrm{CFU} / \mathrm{m}$. Bacteria and bacteriophage lysate (MOI 0.01 ) were added to the samples and incubated at room temperature and $4{ }^{\circ} \mathrm{C}$, overnight. Lysates were diluted in SM buffer and enumerated using spread plate method to count the bacterial reduction $[5,13]$.

\section{Results}

\section{Bacteriophage titer}

A total of 5 bacteriophages were successfully purified which were K EPEC, BI EPEC, BL EPEC, CI EPEC and CS EPEC. From this study, we found that BL EPEC bacteriophage showed the highest titer with a titer value of $2.05 \times 10^{9} \mathrm{PFU} / \mathrm{mL}$. The lowest titer was shown by BI EPEC bacteriophage with a titer of $3.33 \times 10^{8} \mathrm{PFU} / \mathrm{mL}$. Whereas K EPEC was $1.57 \times 10^{9} \mathrm{PFU} / \mathrm{mL}$, CI EPEC was $1.40 \times 10^{9}$, and CS EPEC was $1.67 \times 10^{9} \mathrm{PFU} / \mathrm{mL}$.

\section{$\mathrm{pH}$ and thermal stability assay}

All of bacteriophage were stable upon exposure to $\mathrm{pH}$ 4-10, whereas there were no recoverable bacteriophage upon exposure to $\mathrm{pH} 14$ (Fig. 1a). All of Bacteriophage were also stable upon heating from 4 to $75{ }^{\circ} \mathrm{C}$ with the highest titer found from treatment at $4{ }^{\circ} \mathrm{C}$ (Fig. 1b). Bacteriophage titer was constantly declining with the rise of temperature.

\section{Morphology analysis}

Morphology analysis was done for K EPEC, BI EPEC, and CS EPEC bacteriophage, since the analysis using TEM for BL EPEC and CI EPEC bacteriophage had been done in previous study [10]. TEM results showed that all bacteriophage samples had an icosahedral head and a tail (Fig. 2a). Based on the measurement, the tail diameter for K EPEC bacteriophage was $10 \mathrm{~nm}, 19 \mathrm{~nm}$ for BI EPEC, 


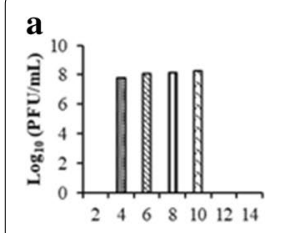

(a)

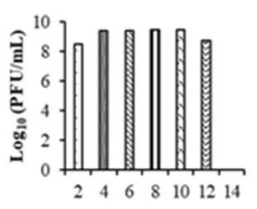

(b)

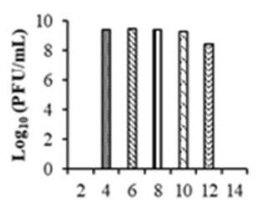

(c)

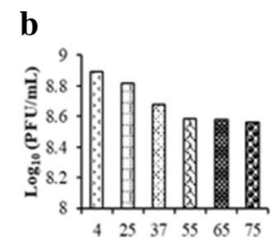

(a)

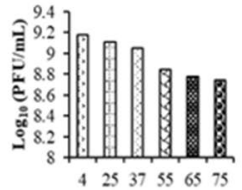

(b)

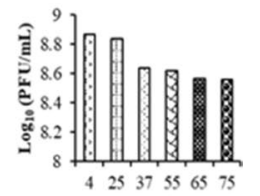

(c)

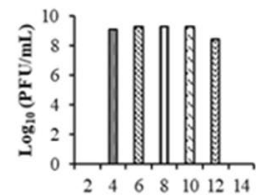

(e)

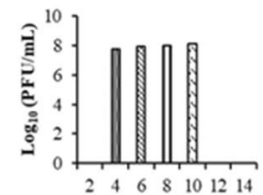

(d)

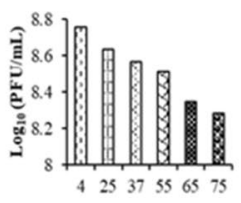

(d)

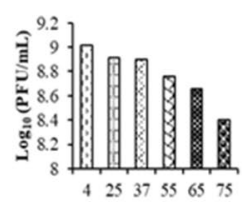

(e)

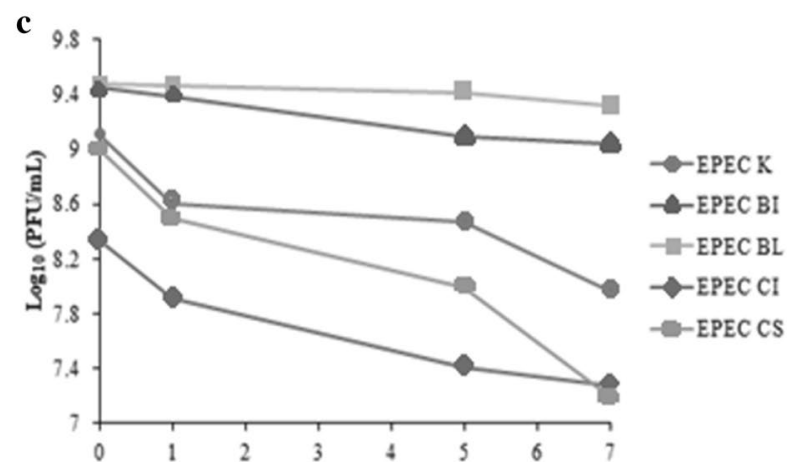

Fig. 1 Stability of bacteriophage (a) KEPEC, (b) BI EPEC, (c) BL EPEC, (d) CI EPEC, (e) CS EPEC. a Stability on different pH values b Stability on different temperatures $\mathbf{c}$ Stability of bacteriophage during storage without the presence of its bacterial cell host

and $17 \mathrm{~nm}$ for CS EPEC, while the tail length was $133 \mathrm{~nm}$ for K EPEC, $82 \mathrm{~nm}$ for BI EPEC, and $86 \mathrm{~nm}$ for CS EPEC.

\section{Storage stability analysis}

Deterioration of viable bacteriophage titer was occurred after $168 \mathrm{~h}$ of incubation without the presence of a bacterial host. BL EPEC bacteriophage showed the least reduction with a reduction of $0.16 \log 10$ and reduction rate of $0.90 \times 10^{-3} \log _{10}$ per hour while CS EPEC bacteriophage showed the most reduction with a reduction of $1.80 \log _{10}$ and reduction rate of $1.08 \times 10^{-2} \log _{10}$ per hour (Fig. 1c).

\section{Minimum inhibitory multiplication of infection (miMOI)}

The greatest MOI tested was 1000 which was equivalent to $1000 \mathrm{PFU}$ per $1 \mathrm{CFU}$ and the least MOI tested was 0.001. BL EPEC and CS EPEC had the least miMOI, which were 0.01, BI EPEC was 10 and was the greatest miMOI, and Both K EPEC and CI EPEC were 0.1 (Fig. 2b).

\section{Application of bacteriophage}

The application of bacteriophage was used to assess the ability of bacteriophages in infecting the host bacteria on various food matrix. Food samples were artificially contaminated with EPEC, and bacteriophage used in this application was BL EPEC with MOI value of 0.01 . The result showed that BL EPEC was able to reduce the bacteria concentration on lettuce and milk samples with reduction above $0.24 \log _{10}$. However, BL EPEC was not able to reduce bacteria concentration on tofu, chicken meat and shrimp samples (Table 1).

\section{Discussions}

In this study, bacteriophage titers were observed between $10^{8}$ and $10^{9} \mathrm{PFU} / \mathrm{mL}$. This variation could be caused by differences in bacteriophage stability under certain conditions. Clear plaques were also formed on the agar plate, indicating the presence of lytic bacteriophages [14].

In general, most bacteriophages are stable under pH 4-11 [15]. BI EPEC, BL EPEC, and CS EPEC had a broader $\mathrm{pH}$ range compared to the other bacteriophages used in this study. The difference between bacteriophage stability in various $\mathrm{pH}$ can be caused by the difference in each isoelectric point. Bacteriophages were most likely to form aggregate when the $\mathrm{pH}$ was lesser or equal to their isoelectric point [16], hence decreasing their effectiveness to infect bacterial cells. As for thermal stability, all of bacteriophage 


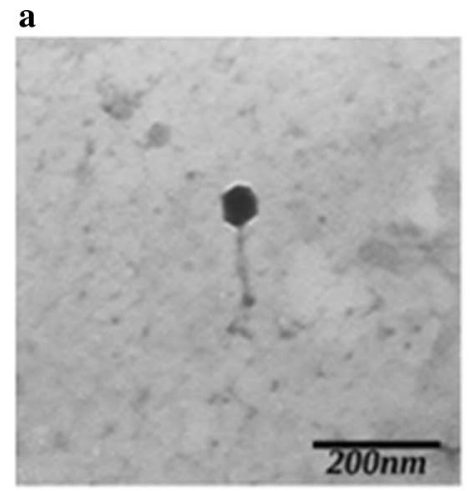

(a)

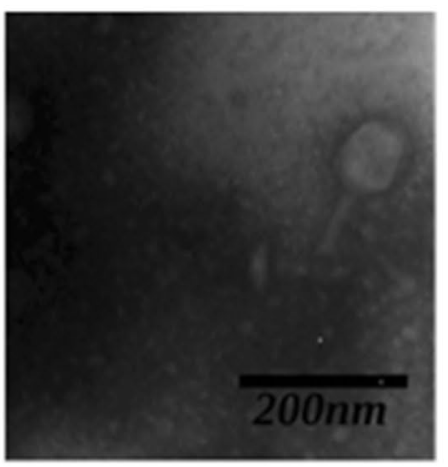

(b)

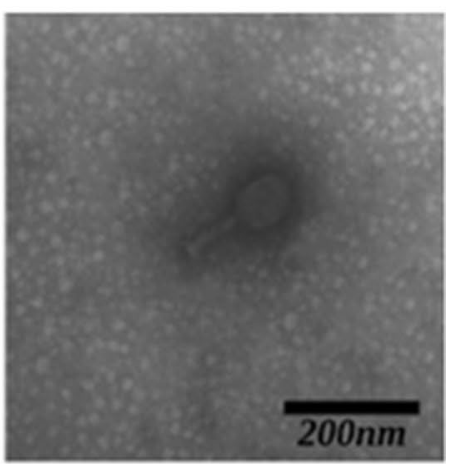

(c)

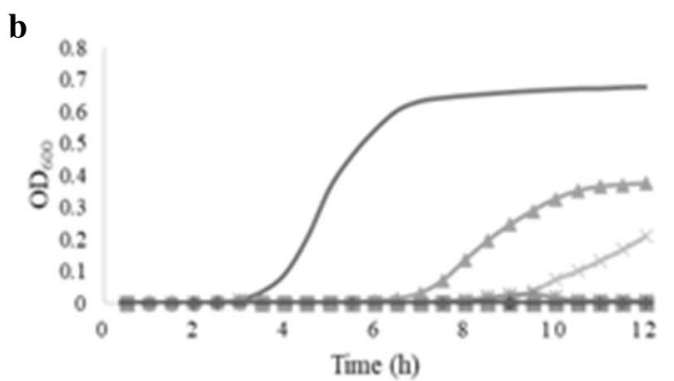

(a)

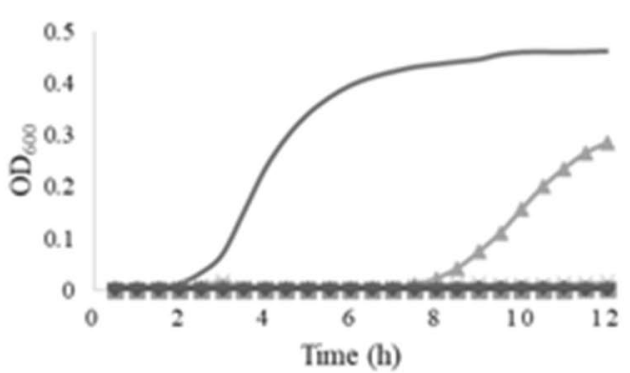

(c)

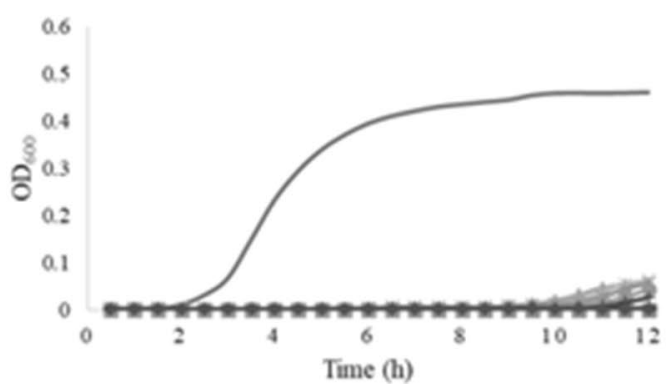

(b)

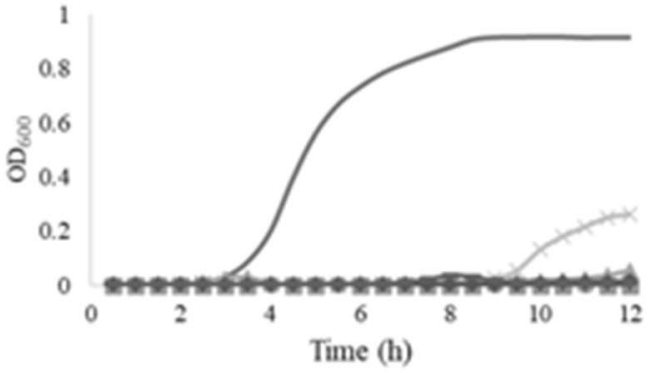

(d)

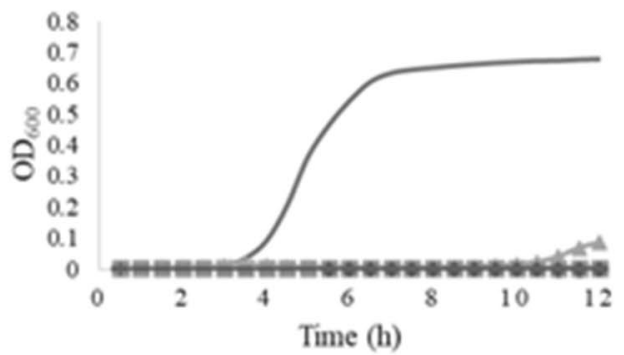

(e)

Fig. 2 a Electron micrographs of bacteriophages (a) KEPEC, (b) BI EPEC, (c) CS EPEC. b The effect of several MOI ratio of bacteriophages (a) KEPEC, (b) BIEPEC, (c) BLEPEC, (d) CS EPEC, and (e) CI EPEC against EPEC bacteria's growth

samples showed a high tolerance toward high temperature. Denaturation of bacteriophage may occur as bacteriophage is mainly composed of nucleic acid and proteins. Upon showing a high tolerance towards high temperature, it was most likely that bacteriophages in this study were able to retain their native folded state 
Table 1 The effectiveness of BLEPEC to various food samples in reducing EPEC

\begin{tabular}{|c|c|c|c|c|c|c|c|}
\hline \multirow[t]{2}{*}{ Samples } & \multirow[t]{2}{*}{ Control (CFU/mL) } & \multicolumn{2}{|c|}{ Number of bacteria (CFU/mL) } & \multicolumn{2}{|c|}{ Reduction (\%) } & \multicolumn{2}{|c|}{ Log reduction $\left(\log _{10}\right)$} \\
\hline & & Room temp. & $4^{\circ} \mathrm{C}$ & Room temp. & $4^{\circ} \mathrm{C}$ & Room temp. & $4^{\circ} \mathrm{C}$ \\
\hline Lettuce & $3.08 \times 10^{8}$ & $1.76 \times 10^{8}$ & $7.8 \times 10^{6}$ & 42.86 & 74.68 & 0.24 & 0.60 \\
\hline Milk & $2.08 \times 10^{8}$ & $3 \times 10^{6}$ & $1 \times 10^{6}$ & 98.56 & 99.52 & 1.84 & 2.32 \\
\hline Tofu & TMTC & $3 \times 10^{6}$ & TFTC & TFTC & TFTC & TFTC & TFTC \\
\hline Chicken meat & $2.85 \times 10^{8}$ & TFTC & TFTC & TFTC & TFTC & TFTC & TFTC \\
\hline Shrimp & $2.3 \times 10^{8}$ & TFTC & TFTC & TFTC & TFTC & TFTC & TFTC \\
\hline
\end{tabular}

TMTC too many to count; TFTC too few to count

when exposed to high temperature [17]. The stability of bacteriophages in this study was similar to previously reported phages having stability in $\mathrm{pH} 4-11,60^{\circ} \mathrm{C}$ [18] and $\mathrm{pH} 4-12,70{ }^{\circ} \mathrm{C}[11]$.

Based on the TEM results, bacteriophages in this study most likely belonged to the Caudovirales order. Td is used to differentiate Myoviridae (td $\geq 16 \mathrm{~nm}$ ) and Siphoviridae (td $<16 \mathrm{~nm}$ ) [19]. From this, it could be assumed that K EPEC bacteriophage belonged to the Siphoviridae, while BI EPEC and CS EPEC belonged to the Myoviridae. However, further analysis such as DNA sequencing is required to confirm the classification of each bacteriophages [20].

Stability of bacteriophages without the presence of a host was observed. Based on the results, BL EPEC bacteriophage exhibited the least reduction. In a study conducted by Huang et al. [11], titer of phage LPSE1 was reduced for $0.5 \log _{10}$ after $168 \mathrm{~h}$ of incubation, with a reduction rate of $2.9 \times 10^{-3} \log _{10}$ per hour.

The miMOI was estimated to be the lowest concentration of phage particles that can inhibit bacterial growth. Each tested phage showed lytic activity against EPEC Nmr-2, and all bacterial growth decreased as the MOI increased. The most effective miMOI was found from BL EPEC and CS EPEC, which was 0.01. Synnott et al. [21] and Bicalho et al. [12] also stated that miMOI value from Staphylococcus aureus and Escherichia coli phage was 0.01 and the most ideal MOI was the lowest. A greater MOI value will result in a rapid lytic activity as the bacteriophage replicates faster [22].

The effectiveness of application of bacteriophage as food preservative depended on several factors, such as food matrix, surface area, contact time, structure, bacterial load, dose of bacteriophage, and presence of other compounds $[20,23]$. Based on the results, food samples lettuce and milk showed a compelling reduction of bacteria both at $4{ }^{\circ} \mathrm{C}$ and room temperature (Table 1). However, the reduction on other samples was below the detectable level. It might be happened due to the capability of phages in lysing the entire bacteria.
Bacterial suspension that was added into food samples might be trapped within the protein network of the matrix, therefore the phages were not able to reach the bacteria $[13,24]$. At a temperature $<12{ }^{\circ} \mathrm{C}$, phages were unable to infect host cells because the viable cells were inactivated, and phage requires the active growth phase of bacteria for replication [25, 26]. Phages that were kept at cold temperatures were more stable and still had a high titer compared to room temperature storage. However, the lytic activity at or above $15{ }^{\circ} \mathrm{C}$ is more effective in reducing the number of bacteria found in food because phage replication still occurs [23, 27]. Further research is required regarding the application of phage to improve food safety including experiments in different food matrices.

In conclusion, all of the bacteriophages were consider stable under specific $\mathrm{pH}$, thermal and storage conditions with high titer. From five bacteriophages that had been purified and characterized, BL EPEC bacteriophage showed the greatest potency and had promising results to be used as a food preservative. BL EPEC bacteriophage showed high $\mathrm{pH}$ and thermal tolerance with the least reduction after $168 \mathrm{~h}$ of incubation without the presence of a bacterial cell host. Application of $\mathrm{BL}$ EPEC into various foods also effective to reduce bacterial growth.

\section{Limitation}

Further study is still needed to be done to screen the effectiveness of this phage against other food-borne pathogens. Application of this phage in other variety of food also need to be explored. Molecular characterization also needs to be conducted for each bacteriophages.

\section{Abbreviations}

EPEC: Enteropathogenic Escherichia coli; LB: Luria-Bertani medium; miMOI: Minimum multiplicity of infection; SM: Sodium-Magnesium buffer.

\section{Acknowledgements}

We would like to thank to Namru-2 in providing isolate of EPEC-Nmr2. 


\section{Authors' contributions}

DEW involved in research design and advisory. AM, CPK and GG conducted the research, collected the data, analyzed and processed the data, and prepared the manuscript. SM and DL involved in microbiology and food analysis advisory. All authors read and approved the final manuscript.

\section{Funding}

This study was Funded by the Ministry of Education of Indonesia-2019. The funder has no contribution in this study.

\section{Availability of data and materials}

The datasets used and/or analysed during the current study are available from the corresponding author on reasonable request.

\section{Declarations}

Ethics approval and consent to participate

Not applicable.

\section{Consent for publication}

Not applicable.

\section{Competing interests}

The authors declare that they have no competing interests.

\section{Author details}

1 Department of Biotechnology, Atma Jaya Catholic University of Indonesia, Jalan Jenderal Sudirman 12930, Jakarta, Indonesia. Department of Food Technology, Atma Jaya Catholic University of Indonesia, Jalan Jenderal Sudirman 12930, Jakarta, Indonesia.

Received: 18 June 2021 Accepted: 20 August 2021

Published online: 28 August 2021

\section{References}

1. Frisca F, Lay BW, Waturangi DE. Identification of class 1 integron of Escherichia coli from street foods in Jakarta. J Microbiol Indones. 2007;1(1):15-8.

2. Dini C, de Urazza PJ. Isolation and selection of coliphages as potential biocontrol agents of enterohaemmorhagic and shiga toxin-producing $E$. coli (EHEC and STEC) in cattle. J Applied Microbiol. 2010;109:873-87.

3. World Health Organization. WHO's first ever global estimates of foodborne diseases find children under 5 account for almost one third of deaths. 2015. https://www.who.int/news/item/03-12-2015-who-s-firstever-global-estimates-of-foodborne-diseases-find-children-under-5account-for-almost-one-third-of-deaths. Accessed 14 Nov 2020.

4. Hartland EL, Leong JM. Enteropathogenic and enterohemorrhagic $E$. coli: ecology, pathogenesis, and evolution. Front Cell Infect Microbiol. 2013;3(15):1-3.

5. Spricigo DA, Bardina C, Cortes P, Llagostera M. Use of a bacteriophage cocktail to control Salmonella in food and the food industry. Int J Food Microbiol. 2013;165:169-74

6. Kazi M, Annapure US. Bacteriophage biocontrol of foodborne pathogens. J Food Sci Technol. 2016;53(3):1355-62.

7. Martinez B, Garcia P, Rodriguez A. Swapping the roles of bacteriocins and bacteriophages in food biotechnology. Curr Opin Biotechnol. 2019;56:1-6.

8. Mclntyre L, Billington C, Hudson JA, Withers H. Biocontrol of foodborne bacteria: past, present and future strategies. Food New Zealand. 2007;7:25-32

9. Thung TY, Norshafawatie SBMF, Premarathne JMJK, Chang WS, Loo YY, Kuan CH, New CY, Ubong A, Ramzi OSB, Mahyudin NA, et al. Isolation of food-borne pathogen bacteriophages from retail food and environmental sewage. Int Food Res J. 2017;24(1):450-4.

10. Lukman C, Yonathan C, Magdalena S, Waturangi DE. Isolation and characterization of pathogenic Escherichia coli bacteriophages from chicken and beef offal. BMC Res Notes. 2020;13:8.

11. Huang C, Virk SM, Shi J, Zhou Y, Willias SP, Morsy MK, Abdelnabby HE, Liu J, Wang $X$, Li J. Isolation, characterization, and application of bacteriophage LPSE1 against Salmonella enterica in ready to eat (RTE) foods. Front Microbiol. 2018;9:1046.

12. Bicalho RC, Santos TMA, Gilbert RO, Caixeta LS, Teixeira LM, Bicalho MLS, Machado VS. Susceptibility of Escherichia coli isolated from uteri of postpartum dairy cows to antibiotic and environmental bacteriophages. J Dairy Sci. 2010;93(1):93-104.

13. Tomat D, Casabonne C, Aquili V, Balague C, Quibrtoni A. Evaluation of a novel cocktail of six lytic bacteriophages against shiga toxin-producing Escherichia coli in broth, milk, and meat. Food Microbiol. 2018;76:434-42.

14. Hyman P. Phages for phage therapy: isolation, characterization, and host range breadth. Pharmaceuticals. 2019;12(35):1-23.

15. Ravi Y, Pooja KM, Yadav KDK. Review-bacteriophages in food preservation. Int J Pure App Biosci. 2017;5(3):197-205.

16. Langlet J, Gaboriaud F, Gantzer C. Effects of pH on plaque forming unit counts and aggregation of MS2 bacteriophage. J Appl Microbiol. 2007;103:1632-8.

17. Ahmadi H, Radford D, Kropinski AM, Tim LT, Balamurugan S. Thermalstability and reconstitution ability of Listeria phages P100 and A511. Front Microbiol. 2017:8:2375.

18. Manohar P, Tamhankar AJ, Lundborg CS, Nachimuthu R. Therapeutic characterization and efficacy of bacteriophage cocktails infecting Escherichia coli, Klebsiella pneumoniae, and Enterobacter species. Front Microbiol. 2019;10:574.

19. Ackermann HW, Tiekotter KL. Murphy's law-if anything can go wrong, it will: problems in phage electron microscopy. Bacteriophage. 2012;2:122-9.

20. Chibani CM, Farr A, Klama S, Dietrich S, Liesegang H. Classifying the unclassified: a phage classification method. Viruses. 2019;11(2):195-210.

21. Synnott AJ, Kuang Y, Kurimoto M, Yamamichi K, Iwano H, Tanji Y. Isolation from sewage influent and characterization of novel Staphylococcus aureus bacteriophages with wide host ranges and potent lytic capabilities. Appl Environ Microbiol. 2009;75(13):4483-90.

22. Gonzalez S, Fernandez LK, Gutierrez D, Campelo AB, Rodriguez A, Garcia P. Analysis of different parameters affecting diffusion, propagation, and survival of Staphylophages in bacterial biofilms. Front Microbiol. 2018;9(2348):1-13.

23. Ly-Chatain $\mathrm{MH}$. The factors affecting effectiveness of treatment in phages therapy [review]. Front Microbiol. 2014;5(51):1-7.

24. Guenther S, Huwyler D, Richard S, Loessner MJ. Virulent bacteriophage for efficient biocontrol of Listeria monocytogenes in ready-to-eat foods. Appl Environ Microbiol. 2009;75(1):93-100.

25. Coffey B, Rivas L, Duffy G, Coffey A, Ross RP, McAuliffe O. Assessment of Escherichia coli O157:H7-specific bacteriophages e11/2 and e4/1 c in model broth and hide environments. Int J Food Microbiol. 2011;147:188-94.

26. Wiggins BA, Alexander M. Minimum bacterial density for bacteriophage replication: implications for significance of bacteriophages in natural ecosystems. Appl Environ Microbiol. 1985;49(1):19-23.

27. O'Flynn G, Ross RP, Fitzgerald GF, Coffey A. Evaluation of a cocktail of three bacteriophages for biocontrol of Escherichia coli O157:H7. Appl Environ Microbiol. 2004;70(6):3417-24.

\section{Publisher's Note}

Springer Nature remains neutral with regard to jurisdictional claims in published maps and institutional affiliations. 